\title{
Effect of respiratory muscle training on pulmonary function in preoperative preparation of tobacco smokers $^{1}$
}

\author{
Efeito do treinamento dos músculos respiratórios sobre a função pulmonar \\ no preparo pré-operatório de tabagistas
}

\author{
Carrie Chueiri Ramos Galvan², Antônio José Maria Cataneo ${ }^{3}$ \\ 1. Research performed at Postgraduate Program on General Basis of Surgery, São Paulo State University (UNESP). Botucatu, São Paulo. Brazil. \\ 2. Felow Master degree of Surgery, UNESP. Botucatu, São Paulo. Brazil. \\ 3. PhD, Associate Professor, Thoracic Surgery Division, Department of Surgery. Coordinator of the Postgraduate Program on General \\ Basis of Surgery, UNESP. Botucatu, São Paulo. Brazil.
}

\begin{abstract}
Purpose: To evaluate the effect of utilization of a specific training program of respiratory muscles on pulmonary function in tobacco smokers. Methods: Fifty asymptomatic tobacco smokers with age superior to 30 years were studied, at the moments: $A_{0}$ - initial evaluation followed by protocol of respiratory exercises; $A_{1}$ - reevaluation after 10 minutes of protocol application; and $\mathrm{A}_{2}$ - final reevaluation after 2 weeks of training utilizing the same protocol 3 times per week. The evaluation was realized through measures of maximum respiratory pressures (PImax and PEmax), respiratory peak flow (IPF and EPF), maximum voluntary ventilation (MVV), forced vital capacity $(\mathrm{FVC})$ and forced expiratory volume at the $1^{\text {st }}$ second $\left(\mathrm{FEV}_{1}\right)$. Results: There was no improvement from initial to final evaluation in $\mathrm{FVC}$ and $\mathrm{FEV}_{1}$. But there were significant increases in the variables IPF, EPF, MVV and PImax at evaluations $\mathrm{A}_{1}$ and $\mathrm{A}_{2}$. The PEmax variable increased only at evaluation $\mathrm{A}_{2}$. Conclusion: The application of the protocol of respiratory exercises with and without additional load in tobacco smokers produced immediate improvement in the performance of respiratory muscles, but this gain was more accentuated after 2 weeks of exercise.
\end{abstract}

Key words: Breathing exercises. Maximal voluntary ventilation. Spirometry. Surgery.

\section{RESUMO}

Objetivo: Avaliar o efeito da utilização de um programa de treinamento específico dos músculos respiratórios sobre a função pulmonar em indivíduos tabagistas. Métodos: Foram estudados 50 indivíduos tabagistas assintomáticos com idade superior a 30 anos, nos seguintes momentos: $\mathrm{A}_{0}$ - avaliação inicial seguida do protocolo de exercícios respiratórios; $\mathrm{A}_{1}$ reavaliação após 10 minutos da aplicação do protocolo; $\mathrm{e}_{2}$-reavaliação final após duas semanas de treinamento utilizando o mesmo protocolo três vezes por semana. A avaliação foi realizada através das medidas de pressões respiratórias máximas (PImax. e PEmax.), picos de fluxo respiratórios (PFI e PFE), ventilação voluntária máxima (VVM), capacidade vital Forçada (CVF) e Volume expiratório forçado no primeiro segundo $\left(\mathrm{VEF}_{1}\right)$. Resultados: Não houve melhora na $\mathrm{CVF}$ e $\mathrm{VEF}_{1}$ da avaliação inicial para a final. Houve aumento significativo das variáveis PFI, PFE, VVM e PImax nas avaliações $\mathrm{A}_{1}$ e $\mathrm{A}_{2}$. A variável PEmax. aumentou somente na avaliação $\mathrm{A}_{2}$. Conclusão: A aplicação de protocolo de exercícios respiratórios com e sem carga adicional em indivíduos tabagistas produziu melhora imediata na performance dos músculos respiratórios, mas esta melhora foi mais acentuada após duas semanas de exercício.

Descritores: Exercícios respiratórios. Ventilação voluntária máxima. Espirometria. Cirurgia. 


\section{Introduction}

The deterioration of respiratory muscle function after surgical procedures contributes significantly to prejudiced pulmonary function and to the incidence of postoperative respiratory complications, increasing morbi-mortality. The appearance and degree of importance of these alterations depend as much on anesthesia as on surgical procedure, besides the risks inherent to the patient. The incidence of postoperative pulmonary complications is more frequent in upper abdominal and thoracic surgeries. Among the physiopathological alterations provoked by surgical procedures, the deterioration of respiratory muscular function after surgery contributes significantly to development of postoperative pulmonary complications through harms such deterioration provokes in pulmonary function. As consequences of dysfunction of respiratory muscles, there are consistent reductions in pulmonary flows and volumes, leading to atelectasis, reduction of cough efficiency, increase of respiratory work and diminution of mechanical efficiency of the respiratory muscles. Active smokers have an increased risk of postoperative pulmonary complications. In surgical treatments tobacco smokers present a higher incidence of expectoration and a greater occurrence of pulmonary complications in the postoperative phase. In general one of the primary preoperative requirements is cessation of the smoking habit. Despite this, it is not uncommon that tobacco smokers smoke until a few hours prior to surgery. The recognition of deleterious effects of surgical procedures on respiratory muscles prompted the realization of studies dedicated to evaluation and prevention of harm to the function of respiratory muscles, both pre- and postoperative. ${ }^{1,2}$ The programs of preoperative respiratory muscular training arose with the aim of preventing accentuated dysfunction, postoperatively, in respiratory muscles through improvement of their performance. They are programmed activities that increase the load imposed on a respiratory muscle pump, through increments in frequency, duration and intensity of muscular contraction and, as in training of any skeletal muscle, obey physiological principles of muscular training. ${ }^{3}$ The specific training of respiratory muscles can be obtained through utilization of exercises with and without additional load, which augments muscular work, requiring greater force and resistance. The respiratory exercises can be done as much by use of spontaneous respirations, selected and controlled, as through respirations realized with apparatuses. In respiratory exercises without a load, through voluntary control, it is possible to obtain contractions that modify the volume and depth of respiration. The oscillation of pressure gradients and the modifications in chest-wall conformation facilitate a selective distribution of air flow in accord with the muscular group involved and with the posture adopted by the patient. In exercises realized with apparatuses, the additional load is offered through systems with linear or non-linear loads, against which the patient produces respiratory efforts. The utilization of additional loads permits better control of work intensity, since it is possible to adjust the load according to individual differences, contrary to respiratory exercises without additional load. Preoperative muscular training with apparatuses has been employed with the proposition of increasing respiratory muscular strength. ${ }^{4}$ The time of preoperative preparation described by diverse authors varies according to the program instituted. Orientation programs are customarily brief, and able to occur moments before the surgical procedures or a few days prior; yet the training programs are prescribed with a duration of two weeks or more and aim to improve pulmonary function anterior to surgery. Among other factors, the urgency of surgical procedure, the necessity or not of previous hospitalization and the viability of costs, also influence the time of preoperative preparation. ${ }^{4,5}$ Respiratory exercises applied preoperatively as a form of respiratory muscle training are useful in the prevention of pulmonary complications; however, we would like to have a greater knowledge of their effects on pulmonary function when the protocol is utilized for a short time frame, principally in individual carriers of risk factors for development of postoperative pulmonary complications such as tobacco smoking. So, the objective of the present study was to evaluate the effect of utilization of a training program specific to respiratory muscles, applied over a short time frame, on pulmonary function in tobacco-smoking individuals.

\section{Methods}

The study was realized in clinically asymptomatic tobacco-smoking individuals. The protocol was developed in the Physiotherapy Laboratory of University Hospital (UH) for the Northern Region of Paraná, under orientation of the Post-Graduate Program in General Bases of Surgery at the State University of Sao Paulo (Unesp), Botucatu, Brazil, after having been approved by the Committee on Ethics and Research of the two institutions involved.

Starting from a pilot study, the sample size was determined utilizing a 5\% significance level, a power of $80 \%$, with an expected mean difference between before and after application of the protocol of exercises for the variable maximum voluntary ventilation (MVV) of approximately $4.4 \mathrm{l} / \mathrm{min}$ and a variability of $10.7 \mathrm{l} / \mathrm{min}$. The minimum sample size was determined in 46 individuals.

Criteria for inclusion and exclusion: Individuals included were asymptomatic tobacco smokers with age superior to 30 years, who reported having smoked a minimum of one cigarette per day for at least ten years, 
and still use cigarettes. They must have had a sedentary lifestyle and a high level of understanding and comprehension. To make the population homogeneous, there were included only individuals who presented normal spirometry measure and respiratory pressures, in accord with the norms established by the diretrizes para testes de função pulmonar. ${ }^{6}$ Excluded individuals were those incapable of realizing the protocol of respiratory exercises or who presented difficulty in completing the evaluation of pulmonary function. Sequence of the study: All the participants were submitted to initial evaluation $\left(\mathrm{A}_{0}\right)$, followed by application of the protocol of respiratory exercises with reevaluation $\left(A_{1}\right)$ after 10 minutes of such protocol application. The same protocol of respiratory exercises was realized 3 times per week for a period of 2 weeks and a final reevaluation $\left(\mathrm{A}_{2}\right)$ was done after 2 weeks. The procedures were done in the morning or afternoon 2 hours after the last meal.

Evaluation: The evaluations were done through spirometry and measurement of maximum inspiratory and expiratory pressures (PImax and PEmax). The spirometry was realized with the patient seated, utilizing a portable spirometer $^{\circledR}$ to evaluate forced vital capacity in liters (FVC, 1), forced expiratory volume in the first second in liters (FEV1,1), inspiratory and expiratory peak flow in 1/s (IPF and EPF, $1 / \mathrm{s}$ ) and maximum voluntary ventilation in $1 /$ $\min (\mathrm{MVV}, 1 / \mathrm{min})$. The PImax and PEmax in $\mathrm{cm}_{2} \mathrm{O}$ were measured through analog manovacuometer ${ }^{\circledR}$ with interval from -150 to $+150 \mathrm{cmH}_{2} \mathrm{O}$, previously calibrated. The measurement of PEmax proceeded during maximum expiratory effort after one deep inspiration, approximating the total lung capacity (TLC). The PImax was measured during one inspiratory force after one prolonged maximum expiration to levels approximating residual volume. The values obtained were those observed directly in the manovacuometer, considering, as sustained maximum value, that which the patient maintained for more than 1 second. Three to five acceptable and reproducible maneuvers were done, and three similar measures were chosen with differences of less than 5\% among them. So that force maneuvers would be dependent, an interval of approximately 1 minute was allowed between one maneuver and another. The value utilized for statistical analysis was the greatest of the three measures chosen.

\section{Protocol of exercises}

I. Diaphragmatic reeducation-slow nasal inspiration and oral expiration aiming for an increased excursion of the diaphragm, observed through elevation of the abdomen and lateral expansion of the thorax. There were 15 repetitions done in dorsal decubitus with the inferior members flexed and 15 repetitions in right and left lateral decubitus (Figure 1) II. Profound inspiration - profound nasal inspiration until reaching the TLC followed by one oral expiration after a short pause. Fifteen repetitions were made in dorsal decubitus with the inferior members flexed. During inspiration the arms were elevated. (Figure 2) III. Inspiratory hiccups - short and successive inspirations without periods of apnea, until reaching TLC, followed by a smooth oral expiration until the level of expiratory repose. There were realized 15 repetitions with the individual seated supporting the thorax laterally with the palms of the hands facing upward, creating a light pressure during expiration (Figure 3). IV.Resistive inspiration with linear pressure load - The pressure valve system employed was activated by profound inspiration with a scale from 7 to $41 \mathrm{cmH}_{2} \mathrm{O}$ denominated Threshold - Training Respiratory Muscles ${ }^{\circledR}$. The load utilized varied from 30 to $50 \%$ of the value of PImax. Three series of 15 repetitions were done with intervals for rest (Figure 4).

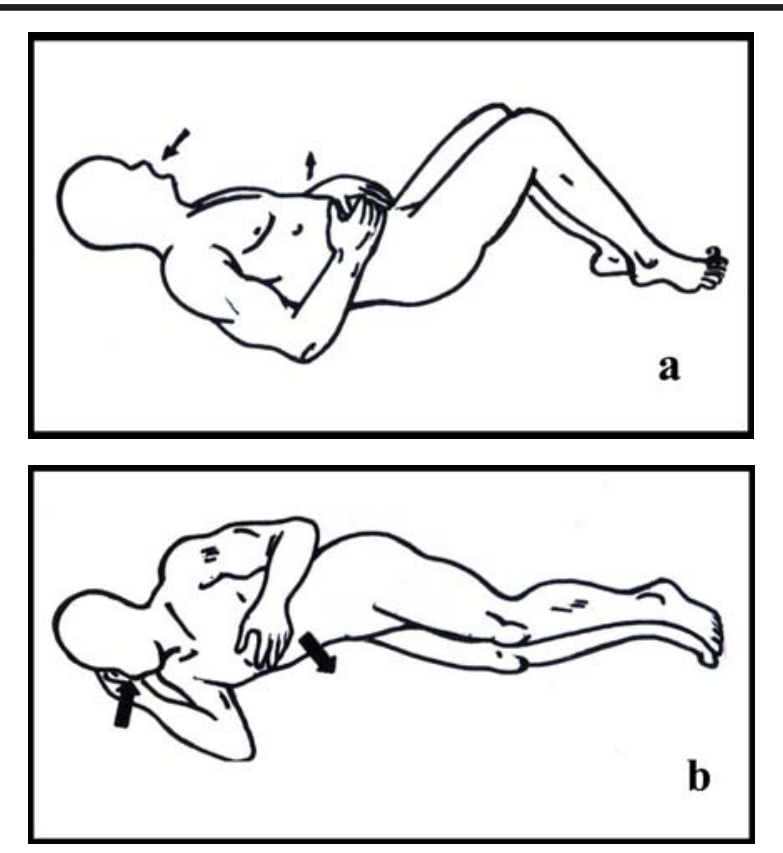

FIGURE 1 - Schematic drawing showing the positioning utilized in dorsal decubitus (a) and in lateral decubitus (b)

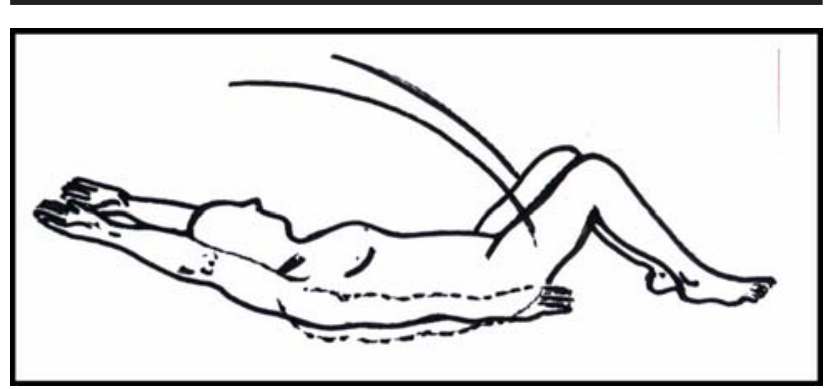

FIGURE 2 - Schematic drawing showing the positioning utilized in dorsal decubitus and the elevation of superior members during inspiration 


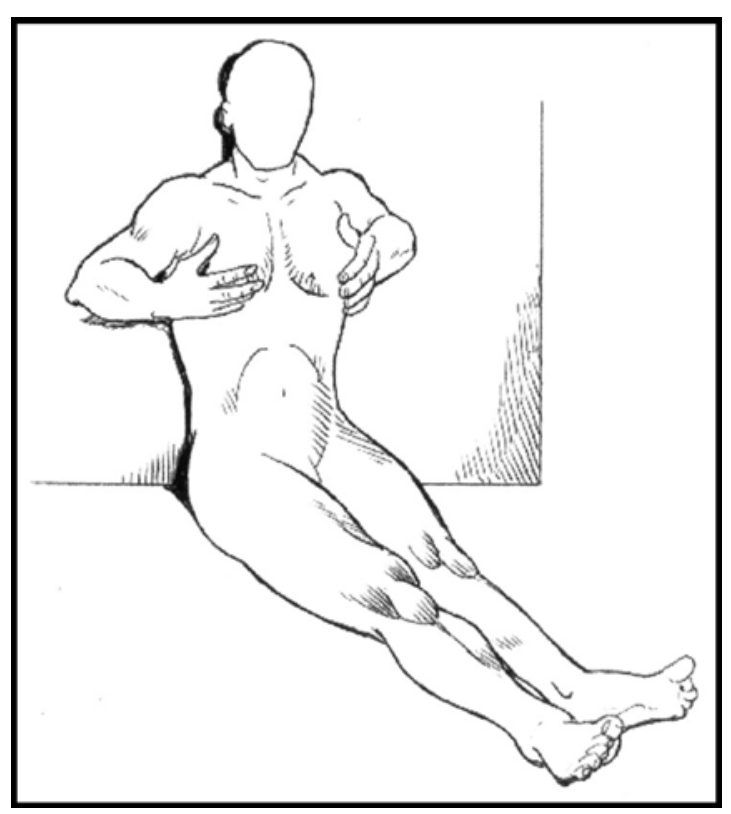

FIGURE 3 - Schematic drawing showing the individual seated with the hands supported on the thorax performing compression during expiration

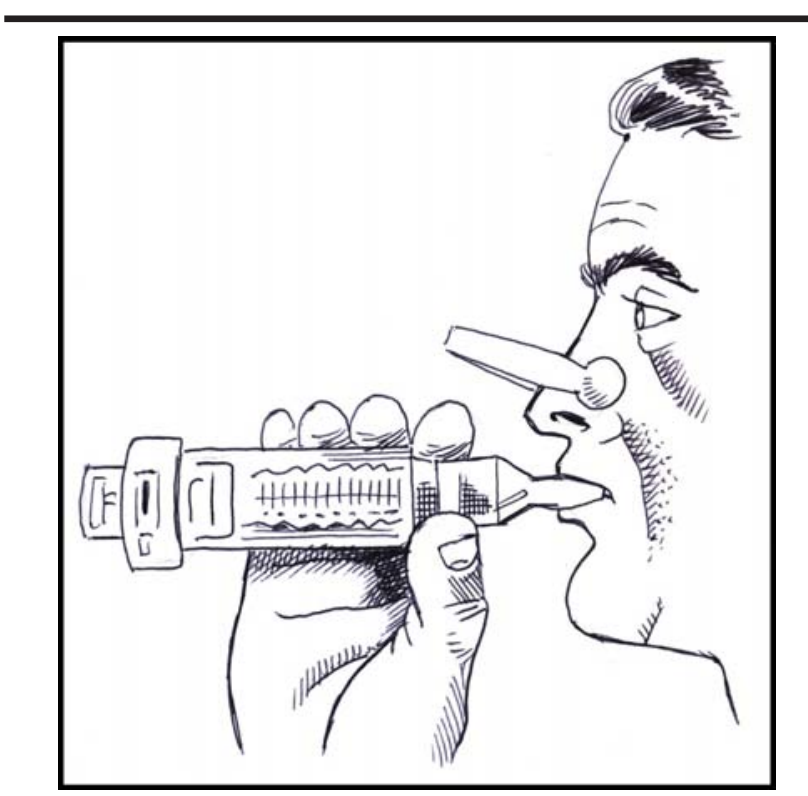

FIGURE 4 - Schematic drawing of utilization of Threshold

\section{Statistical analysis}

For analysis of variables at the studied moments, the tests of Wilcoxon, and Student's t test for paired samples were utilized, respectively, for variables of nonnormal and normal distribution. The level of significance adopted was $5 \%$.

\section{Results}

There were evaluated 50 individuals (28B\&, 22@\&) with age from 30 to 58 years $(\mathrm{x} \pm \mathrm{s}=41.8 \pm 8.0)$. Tobacco consumption varied from 10 to 35 years.pack, with mean value of $18.86 \pm 14.09$ years.pack. Values of means and standard deviations for FVC (1) at evaluations $\mathrm{A}_{0}, \mathrm{~A}_{1}$ and $\mathrm{A}_{2}$ were, respectively, $3.90 \pm 0.85,3.84 \pm 0.85$ and $3.94 \pm 0.83$ and for $\mathrm{FEV}_{1}(\mathrm{l})$ the values were $3.16 \pm 0.69,3.10 \pm 0.66$ and $3.14 \pm 0.56$, and for $\mathrm{FEV}_{1} / \mathrm{FVC}(\%)$ they were $81.33 \pm 5.92$, $80.58 \pm 2.31$ and $79.76 \pm 5.24$, with no improvement from initial to final evaluation (Figure 5). Values of means and standard deviations for EPF $(1 / \mathrm{s})$ at evaluation $\mathrm{A}_{0}, \mathrm{~A}_{1}$ and $\mathrm{A}_{2}$ were, respectively, 7.92 $\pm 2.04,8.40 \pm 2.31$ and $8.81 \pm 2.21$; for IPF $(1 / \mathrm{s})$ they were $6.52 \pm 2.03,7.18 \pm 1.81$ and $7.31 \pm 2.02$, with significantly greater values from evaluation $\mathrm{A}_{1}$ and $\mathrm{A}_{2}$ compared to the initial evaluation $\left(\mathrm{A}_{0}\right)$ in both variables (Figure 6). Values of means and standard deviations for $\operatorname{MVV}(1 / \mathrm{min})$ at evaluations $\mathrm{A}_{0}, \mathrm{~A}_{1}$ and $\mathrm{A}_{2}$ were, respectively, $149,20 \pm 38.6,153.09 \pm 35.4$ and $158.12 \pm 36.6$, with a significant difference among them. The PImax and PEmax $\left(\mathrm{cmH}_{2} \mathrm{O}\right)$ values for the median, and $1^{\text {st }}$ and $3^{\text {rd }}$ quartiles were, respectively, at evaluations $\mathrm{A}_{0}, \mathrm{~A}_{1}$ and $\mathrm{A}_{2}$ : PImax - 85 (75100), 97.5 (85-115) and 110 (90-130); PEmax -122.5 (105-140), 130 (110-145) and 140 (115-150). For both variables there were differences among all moments of evaluation, but not significant in the difference between the evaluations $\mathrm{A}_{0}$ and $A_{1}$ for PEmax (Figure 7).

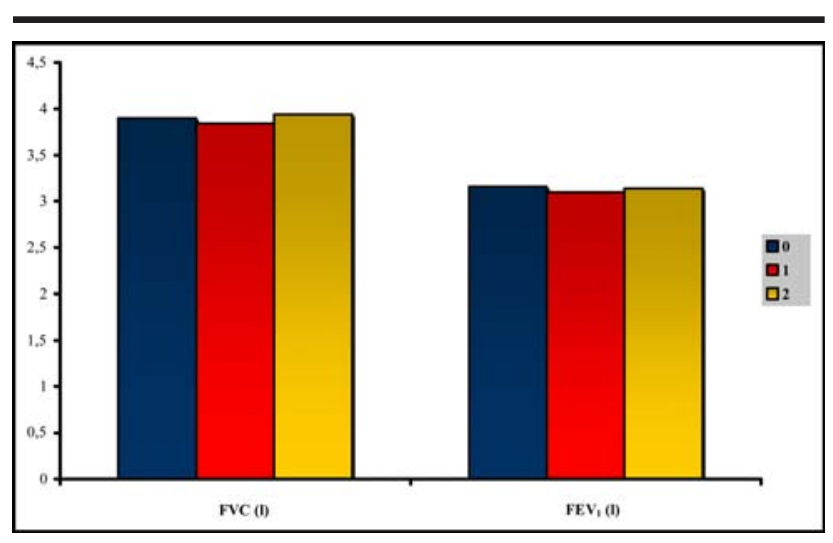

FIGURE 5 - Diagram representing the means of variables FEV1 at evaluations 0,1 and 2

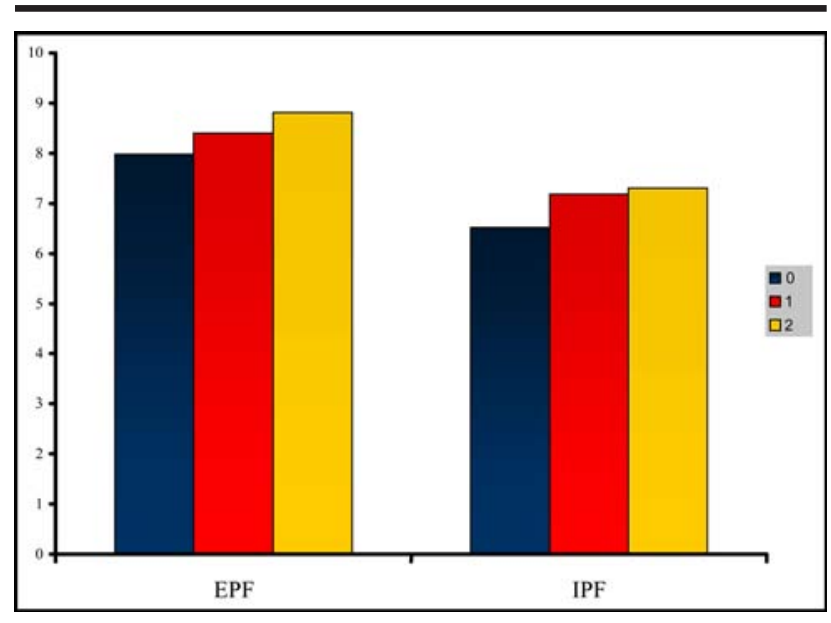

FIGURE 6 - Diagram representing the means of variables EPF and IPF at evaluations 0,1 and 2 


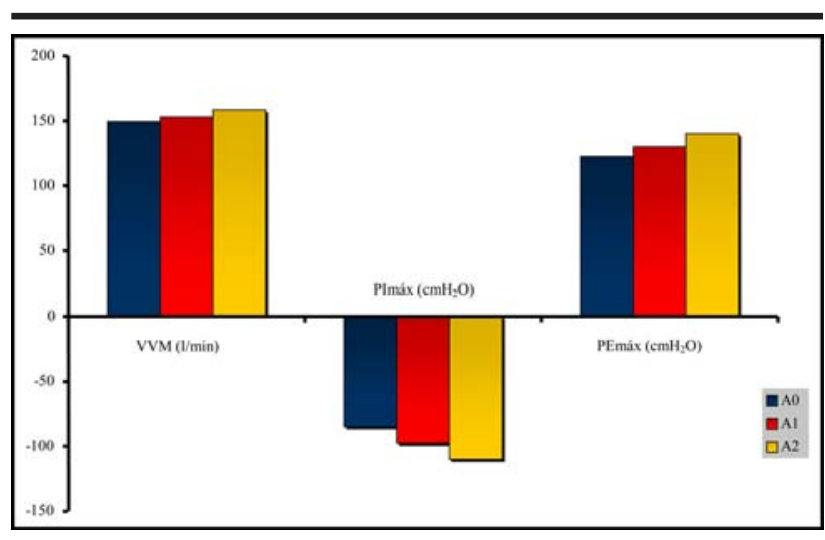

FIGURE 7 - Diagram representing the means of variable (MVV), and medians of variables PImax and PEmax at evaluations 0,1 and 2

\section{Discussion}

In the present study, there was no improvement of $\mathrm{FEV}_{1}$ or FVC after the application of respiratory exercises. Studies that evaluated the behavior of these variables soon after the application of respiratory exercises are scarce and controversial. Campbell ${ }^{7}$ reported that the use of respiratory exercises associated with postural drainage and percussion in patients with exacerbated bronchitis produces an adverse effect on $\mathrm{FEV}_{1}$, verified by a drop in the values of this variable immediately after physiotherapy, returning to normal twenty minutes after.

However, Newton and Stephenson ${ }^{8}$, utilizing physiotherapy in patients with exacerbated bronchitis, did not encounter modifications in FVC and $\mathrm{FEV}_{1}$ immediately after its application. Feldman ${ }^{9}$ evaluating patients with cystic fibrosis and chronic bronchitis with production of a large volume of secretion, which showed a significant increase in $\mathrm{FEV}_{1}$, interpreted this improvement as obtained due to respiratory physiotherapy having removed secretion from the small airways. Since the measures of $\mathrm{FVC}$ and $\mathrm{FEV}_{1}$ are dynamic maneuvers dependent on effort, they can become difficult soon after completion of respiratory exercises. During the realization of muscular exercises with a load, as in the protocol applied herein, modifications occurred in blood supply to the muscles activated, with the objective of furnishing oxygen and removing metabolites. After the exercises, the blood flow continues increasing for a period sufficient to restore the internal equilibrium of the muscle. This can eventually rigidify the muscles thus hindering voluntary command during new solicitations for work. Based solely on volumetric variables, we can say that no improvement occurred in pulmonary function after the protocol of exercises. Despite not having emphasized exercises that trained expiration, there was significant increase in EPF values as much immediately as after two weeks of training with respiratory exercises, when compared to the initial evaluation. In sedentary individuals such as those from the present study, the lack of activities that would stimulate the maximum amplitude of movements of the thorax favors its rigidifying, reducing compliance and increasing the respiratory work through greater energetic expenditure to overcome the elastic resistance of the lung. The respiratory exercises utilized emphasized profound inspiration in its maximum amplitude of movement. The increase of EPF occurred probably through improvement in functional excursion of the thorax. With an increased flexibility, the tension or velocity of contraction generated by expiratory muscles during forced expiration was greater. A specific study that would permit the evaluation of amplitude of thoracic movements is necessary to justify better the EPF increment after the exercises. Immediately after the respiratory exercises and after two weeks of training there was a significant increase in IPF values compared to the initial evaluation. This occurred probably from improvement in efficiency of inspiratory muscles in producing a faster muscular contraction by virtue of recruitment of a greater number of muscular fibers during the effort, thus increasing the strength of inspiratory muscles. It is probable that, postoperatively, the presence of retention of secretions, the reduction of pulmonary volumes and the modifications in the respiratory pattern might be minimized through the generation of high inspiratory flows. Increased IPF values can aid in the execution of maneuvers of profound inspiration, useful in pulmonary reexpansion and in the cough mechanism. We verified that, after the utilization of exercises, a significant increase in PImax occurred, indicating an improvement in strength of inspiratory muscles. One of the principal goals of exercise is development of strength. An important factor that affects the capacity of a muscle for an increase of force is recruitment of a greater number of motor units during exercise. The greater the number of motor units activated, the greater the production of force. We believe that because of the utilization of resisted inspiratory exercises the ability of inspiratory muscles was trained to recruit a greater number of motor units during maximum inspiration. The rapid gain of strength at evaluation 1 also could have been a consequence of the effect of learning, by virtue of neurophysiological adaptation to the task imposed during the exercise. The effects of training and force on the central nervous system include an increase in ability to recruit muscular fibers of muscles used in training. The protocol of exercises utilized in our study probably had made the inspiratory muscles more adroit for realization of PImax measures. At evaluation 1 there occurred no modifications in values of PEmax compared to the initial evaluation. The exercises utilized in our protocol emphasized only the inspiratory muscles and, therefore, we did not expect improvement in force of expiratory muscles. As in the case of PImax, MVV 
demonstrated a significant increase in its values soon after realizing the protocol of exercises. MVV can indicate the function of respiratory muscles since it depends on the capacity that they have to generate force and, in response to the use of respiratory exercises with increased load, can be elevated. We believe, therefore, that the values of MVV increased on account of improved strength of inspiratory muscles. The rapid gain of strength in inspiratory muscles in the preoperative phase can be useful in recruitment of these muscles for postoperative pulmonary expansion, although we did not find studies that confirmed this possibility. After two weeks of training we found a still greater increase in PImax and MVV, together with elevation of PEmax values. All the values increased significantly compared to the initial evaluation. Improvement in mechanical efficiency of respiratory muscles can be obtained through an adequate program of specific training. In the same manner as skeletal muscles, respiratory muscles can modify their strength and endurance. ${ }^{10}$ In long-term training programs, improvement of strength is related to increase in synthesis of the contractile proteins actin and myosin, yet improvement of endurance of the skeletal muscles is associated with improvement in their oxidative capacity through increase in levels of oxidative enzymes, of reserves of lipids and glycogen and of the number of capillaries. Various reports suggest that the capacity of respiratory muscles can increase through appropriate stimuli that augment the load imposed on them and, thus the training of respiratory muscles aims to facilitate these types of cellular changes in the muscles activated. Since Leith and Bradley ${ }^{10}$ showed increase of strength and endurance in healthy individuals, a substantial number of studies have followed on the effects of inspiratory muscular training in various disorders including neuromuscular diseases, chronic obstructive pulmonary disease, failure in weaning from mechanical ventilation, kyphoscoliosis and thoracic-abdominal surgeries. . $^{4,11,12}$ These disorders have in common a weakness of respiratory muscles and, therefore, they are frequently associated with respiratory failure during repose or exercise. A majority of the studies realized showed that specific training of respiratory muscles produces augmented strength and endurance. ${ }^{12}$ The increase in PImax values indicates improvement in strength of inspiratory muscles. Despite not utilizing specific exercises for the expiratory muscles, there occurred also a significant increase in PEmax at the final evaluation. This rise occurred probably due to variations in the relation between length and tension generated by the muscles. During inspiration, a distension of the abdominal wall by descent of the diaphragm augments the tension stored by the expiratory muscles, facilitating the production of strength during a forced expiration starting from TLC. We understand that the improvement in strength of inspiratory muscles contributed to an increase in pulmonary volume on account of a greater amplitude of movement of the thorax and abdomen during inspiration. The greater diminishment of inspiratory muscles produced a greater tension on the expiratory muscles during the PEmax maneuver, resulting in increasing values. Higher PEmax values can be useful in production of a more effective cough postoperatively, which is important in the prevention of retention of secretions. In the final evaluation a significant increase occurred also in MVV values. Considering that this variable is useful in evaluating maximum ventilatory capacity of an individual, and in the presence of normal expiratory flows reflect the combination between the production of force and endurance, we believe that specific training of respiratory muscles with the protocol utilized was useful in improving the force and endurance of respiratory muscles. The benefits of training, in isolation, still are not obvious since, in the majority of respiratory dysfunctions, a high endurance level is a primary requirement. For development of endurance, it should be noted that strength training is an essential part; and as the strength of a muscle increases, its resistance to fatigue and potency also increases. The endurance of respiratory muscles can be affected by a disproportionate increase in demand for respiratory work or by a reduction in energy supply during their contraction, creating a predisposition to muscular fatigue. The surgical procedures affect the function of respiratory muscles and can provoke both alteration in demand and availability of energy for contraction of these muscles. ${ }^{13}$ The training of respiratory muscles can be useful in the prevention of fatigue. It is believed that development of endurance of respiratory muscles makes respiration more efficient with the production of higher flow volumes with low frequencies and a smaller energetic expenditure. In general the time described by various authors for endurance training is from 4 to 8 weeks, although a period of two weeks is cited as a minimum for obtaining results. ${ }^{14}$ The results obtained in relation to variables of force and endurance confirm the findings of diverse studies utilizing specific training of respiratory muscles in asymptomatic individuals, with chronic or other pulmonary diseases $;^{4,5,10,11}$ and in surgical patients various reports have shown the efficacy of respiratory muscle training on pulmonary function, thus reducing postoperative pulmonary complications. ${ }^{2,4,15}$ In this context we understand that the protocol of exercises in our study was useful in the improvement of muscular performance in tobacco-smoking individuals and that this can contribute to a reduced time of preoperative preparation, to minimization of postoperative respiratory muscular dysfunction and to prevention of respiratory complications. We know, however that more studies on this subject are necessary for confirmation of these benefits. 


\section{Conclusion}

The application of the protocol of respiratory exercises with and without additional load in individual tobacco smokers produced improvement in performance of respiratory muscles immediately after its utilization and after two weeks of training, with the latter being superior.

\section{References}

1. Pasquina P, Tramer MR, Walder B. Prophylactic respiratory physiotherapy after cardiac surgery: systematic review. BMJ. 2003;327(7428):1379.

2. Varela G, Ballesteros E, Jimenez MF, Novoa N, Aranda JL. Cost-effectiveness analysis of prophylactic respiratory physiotherapy in pulmonary lobectomy. Eur J Cardiothorac Surg. 2006; 29(2):216-20.

3. American College of Sports Medicine. Diretrizes do ACSM para os testes de esforço e sua prescrição. 6.ed. Rio de Janeiro: Guanabara-Koogan; 2000.

4. Nomori H, Kobayashi R, Fuyuno G, Morinaga S, Yashima H. Preoperative respiratory muscle training. Assessment in thoracic surgery patients with special reference to postoperative pulmonary complications. Chest. 1994;105(6):1782-8.

5. Rajendran AJ, Pandurangi UM, Murali R, et al. Preoperative short-term pulmonary rehabilitation for patients of chronic obstructive pulmonary disease undergoing coronary artery bypass graft surgery. Indian Heart J. 1998;50(5):531-4.
6. Diretrizes para testes de função pulmonar. J Pneumol. 2002;28 (Supl 3):S1-S238.

7. Campbell AH, O'Connell JM, Wilson F. The effect of chest physiotherapy upon the $\mathrm{VEF}_{1}$ in chronic bronchitis. Med J Aust.1975;1(2):33-5.

8. Newton DA, Stephenson A. Effect of physiotherapy on pulmonary function: a laboratory study. Lancet.1978;2(8083):228-9.

9. Feldman J, Traver GA, Taussig LM. Maximal expiratory flows after postural drainage. Am Rev Respir Dis. 1979;119(2):239-45.

10. Leith DE, Bradley M. Ventilatory muscle strenght and endurance training. J Appl Physiol. 1976;41(4):508-16.

11. Pulmonary rehabilitation-1999. American Thoracic Society. Am J Respir Crit Care Med. 1999;159(5 Pt 1);1666-82.

12. Fregonezi GA, Resqueti VR, Guell R, Pradas J, Casan P. Effects of 8-week, interval-based inspiratory muscle training and breathing retraining in patients with generalized myasthenia gravis. Chest. 2005;128(3):1524-30.

13. Siafakas NM, Mitrouska I, Bouros D, Georgopoulos D. Surgery and the respiratory muscles. Thorax. 1999;54(5):458-65.

14. Ghorayeb N, Barros TLN. O exercício: preparação fisiológica, avaliação médica, aspectos especiais e preventivos. São Paulo: Atheneu; 1999.

15. Westerdahl E, Lindmark B, Eriksson T, Friberg O, Hedenstierna G, Tenling A. Deep-breathing exercises reduce atelectasis and improve pulmonary function after coronary artery bypass surgery. Chest. 2005;128(5):3482-8.

\section{Correspondence:}

Antônio José Maria Cataneo

Universidade Estadual Paulista - Faculdade de Medicina

Departamento de Cirurgia e Ortopedia

18618-970 Botucatu - SP Brazil

Phone: (55 14)3811-6091

Fax (55 14)3815-7615

Celular:(55 14)9775-3452

acataneo@,fmb.unesp.br
Conflict of interest: none Financial source: none

Received: November 21, 2006

Review: December 14, 2006

Accepted: January 10, 2007

\section{How to cite this article:}

Galvan CCR, Cataneo AJM. Effect of respiratory muscle training on pulmonary function in preoperative preparation of tobacco smokers. Acta Cir Bras. [serial on the Internet] 2007 Mar-Apr;22(2). Available from URL: http://www.scielo.br/acb 